aneurysms and to purpose workflow for classification and significance

Materials and Methods This was a cross-sectional, retrospective study conducted on 650 patients referred for cerebral DSA at our institution from January 2020 to February 2021. DSA images were analyzed by two interventional

\begin{tabular}{|c|c|c|}
\hline $\begin{array}{l}\text { Variation in vessel } \\
\text { origin }\end{array}$ & \multicolumn{2}{|c|}{ Variation in the number of vessels } \\
\hline Infundibulum 8\% & \multicolumn{2}{|l|}{ Reduced Number } \\
\hline Common origin & \multicolumn{2}{|l|}{ Aplasia of A1 $0.4 \%$} \\
\hline AICA/PICA 15\% & \multicolumn{2}{|l|}{ Azygos A1 1\% } \\
\hline SCA/PCA 4\% & \multicolumn{2}{|c|}{ Absence of Acom/Absence of Pcom 0\% } \\
\hline $\begin{array}{l}\text { Persistent Embryological } \\
\text { Circulation }\end{array}$ & \multicolumn{2}{|l|}{ ICA Agenesis $0.31 \%$} \\
\hline $\begin{array}{l}\text { Persistent dorsal } \\
\text { ophthalmic artery } 0.31 \%\end{array}$ & \multicolumn{2}{|l|}{ Artery of Percheron $0.46 \%$} \\
\hline Fetal PCA- & \multicolumn{2}{|l|}{ Incresed Number } \\
\hline $\begin{array}{l}\text { unilateral/bilateral } 10 \% / \\
2 \%\end{array}$ & \multicolumn{2}{|l|}{ Accessory MCA $0.15 \%$} \\
\hline $\begin{array}{l}\text { Cavernous origin of } \\
\text { ophthalmic artery } 0 \%\end{array}$ & \multicolumn{2}{|l|}{ Duplication BA $0.31 \%$} \\
\hline $\begin{array}{l}\text { MMA origin of ophthalmic } \\
\text { artery } 0.15 \%\end{array}$ & \multicolumn{2}{|l|}{ MCA $0 \%$} \\
\hline $\begin{array}{l}\text { MMA origin of lacrimal } \\
\text { artery } 0.31 \%\end{array}$ & \multicolumn{2}{|l|}{ SCA $0.7 \%$} \\
\hline & \multicolumn{2}{|l|}{ AcomA $0 \%$} \\
\hline & \multicolumn{2}{|l|}{ Trifurcation } \\
\hline & \multicolumn{2}{|l|}{ ACA $0.3 \%$} \\
\hline & \multicolumn{2}{|l|}{ MCA $1.7 \%$} \\
\hline VARIATION IN THE & VARIATION IN THE & ASSOCIATION WITH \\
\hline MORPHOLOGY & PATHWAY & ANEURYSMS \\
\hline Hypoplasia & $\begin{array}{l}\text { Persistence Embryological } \\
\text { Anastomosis }\end{array}$ & $12.60 \%$ \\
\hline ICA $0.15 \%$ & $\begin{array}{l}\text { Persistent carotid } \\
\text { vertebrobasilar Anastomosis }\end{array}$ & \\
\hline A1 $7.7 \%$ & PTA $0.31 \%$ & \\
\hline $\begin{array}{l}\text { A2 -Bihemispheric ACA } \\
6 \%\end{array}$ & PPHA $0 \%$ & \\
\hline Pcom 3\% & $\begin{array}{l}\text { Proatlantial intersegmental } \\
\text { artery } 0 \%\end{array}$ & \\
\hline VA $1.4 \%$ & $\begin{array}{l}\text { Persistent internal -external } \\
\text { Anastomosis }\end{array}$ & \\
\hline Right -left dominent & $\begin{array}{l}\text { Aberrant Intratympanic } \\
0.15 \%\end{array}$ & \\
\hline Left -right dominent & $\begin{array}{l}\text { Persistent Stapedial Artery } \\
0 \%\end{array}$ & \\
\hline Terminates as PICA $0.2 \%$ & & \\
\hline Hyperplasia & & \\
\hline AchoA & & \\
\hline Fenestration & & \\
\hline A1 $0 \%$ & & \\
\hline A2 $0.15 \%$ & & \\
\hline Acom $0.15 \%$ & & \\
\hline VB Junction $0.46 \%$ & & \\
\hline BA $0.15 \%$ & & \\
\hline Early Bifurcation -MCA & & \\
\hline Frequent & & \\
\hline
\end{tabular}

neuroradiologists with several years of experience in neurointervention to determine the final configuration of the circle of Willis, normal variants, and the presence of vascular anomalies.

Results Arterial fenestrations were found in $0.75 \%$ of patients, with the vertebrobasilar system as common location $(0.46 \%)$. The remaining fenestrations were located at the basilar artery apex $(0.1 \%)$, anterior communicating artery $(0.1 \%)$, and distal anterior cerebral artery A2-A3 segment $(0.1 \%)$. The prevalence of an azygos anterior cerebral artery was $1 \%$. Bihemispheric anterior cerebral artery was found in $6 \%$, hypoplastic A1 segment in 7.7\%, and congenital absence of A1 segment in $0.4 \%$ of patients. Fetal origin of the posterior cerebral artery was found in $12 \%$ of cases. Hypoplastic vertebral artery, right, left, or terminating as posterior inferior cerebellar artery was observed in $1.4 \%$ of patients. Trifurcation is more common at the middle cerebral artery junction observed in $1.7 \%$ of cases. Accessory middle cerebral artery were seen in $0.15 \%$ of cases. Duplications were common in superior cerebellar artery $(0.7 \%$ cases $)$ and in basilar artery in $0.31 \%$ of cases. All kinds of persistent carotid-basilar anastomosis were present in our series including persistent trigeminal artery in $0.3 \%$ cases. Persistent internal carotid anastomosis as aberrant intratympanic course of ICA in $0.15 \%$ of cases. Others include meningolacrimal and meningo-ophthalmic variants in $0.46 \%$ cases. In $0.3 \%$ of cases, the dorsal ophthalmic artery was arising from the cavernous segment. $12.6 \%$ of aneurysms were associated with intracranial variants and anomalies.

Conclusion Knowledge of such variants and anomalies is crucial to differentiate them from pathologies, to understand the etiology of certain pathologies directly related to variants, and to depict the changes in collateral circulation in patients with variants. Detection of variants may lead to the discovery of cerebrovascular diseases especially aneurysms, and may also affect planning of endovascular or neurosurgical interventions. This study is intended to serve as a guide for daily use in clinical practice.

Disclosures S. Ahmad: None.

\section{E-143 VIRTUAL AVM EMBOLIZATION - A TOOL FOR ADVANCED INTERVENTIONAL TREATMENT PLANNING}

${ }^{1} \mathrm{D}$ Behme*, ${ }^{2} \mathrm{U}$ Sprengel, ${ }^{2} \mathrm{~J}$ Stahl, ${ }^{3} \mathrm{P}$ Saalfeld, ${ }^{3} \mathrm{~B}$ Behrendt, ${ }^{1} \mathrm{M}$ Thormann, ${ }^{1} \mathrm{~A}$ Mpotsaris, ${ }^{3}$ B Preim, ${ }^{4} \mathrm{P}$ Berg, ${ }^{5} \mathrm{~S}$ Saalfeld. 'Neuroradiology, University Clinic Magdeburg, Magdeburg, Germany; ${ }^{2}$ Research Campus Stimulate, University Magdeburg, Magdeburg, Germany; ${ }^{3}$ Department of Simulation and Graphics, University Magdeburg, Magdeburg, Germany; ${ }^{4}$ Research Campus Stimulate; Department of Fluid Mechanics and Technical Flows, University Magdeburg, Magdeburg, Germany; ${ }^{5}$ Research Campus Stimulate; Department of Simulation and Graphics, University Magdeburg, Magdeburg, Germany

\subsection{6/neurintsurg-2021-SNIS.238}

Introduction/Purpose Interventional treatment of arteriovenous malformations (AVMs) using liquid embolics is challenging especially in larger AVMs with multiple feeding arteries. Premature occlusion of the draining vein(s) may lead to fatal AVM rupture and sequential occlusion of different feeding arteries is associated with the risks of incomplete AVM occlusion or may increase rupture risk by causing hemodynamic imbalance during the embolization procedure. Virtual AVM embolization is a tool that may help for a better understanding of hemodynamic changes 
during embolization and thus may reduce procedural complications.

Material and Methods 3D AVM surface models were extracted from multimodal image data $3 \mathrm{D}$ digital subtraction image and MRA). For the virtual embolisation, all feeders of each AVM were identified and blocked separately. For $\mathrm{n}$ feeder arteries each blocked or unblocked, a total amount of $n^{2}$ blood flow simulations via computational fluid dynamics (CFD) was carried out. A custom visualization and exploration tool was developed using the Game Engine Unity where blood flow was illustrated via millions of small particles based on the CFD results.

Results The virtual embolisation software prototype allows the clinical expert to explore patient specific AVM models in 3D. Furthermore, the user can select and deselect feeder arteries to block (i.e. to embolize) or unblock them, respectively. Thus, the effects of an individual embolization strategy can be explored by analyzing the subsequent blood flow as well as by interpreting the resulting pressure gradients.
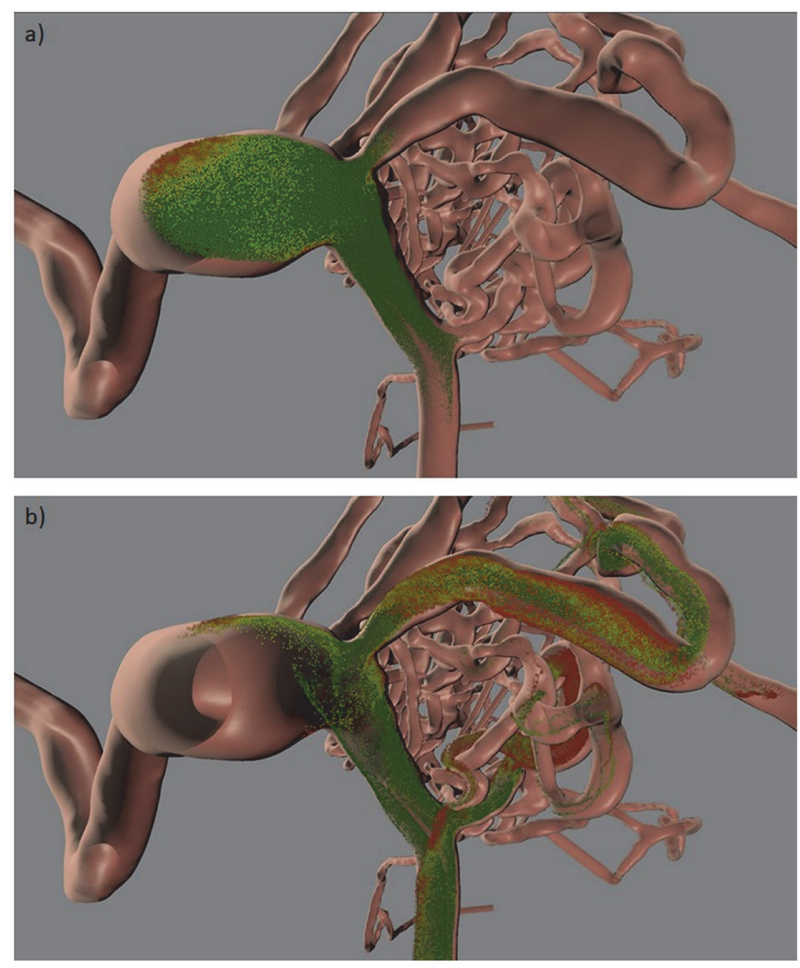

Abstract E-143 Figure 1 Depiction of the introduced AVM blood flow visualization. The user chooses a starting point of blood flow particles in the internal carotid artery and can follow the spread of particles along the feeder arteries to get an impression how the different feeders contribute to the blood supply of the nidus

Conclusion Because the success and safety of AVM treatment is a matter of hemodynamic balance until the draining veins are occluded by the embolization material, virtual AVM embolization is a powerful tool to simulate and explore the hemodynamic changes that occur at different embolization steps prior to AVM treatment.

Disclosures D. Behme: None. U. Sprengel: None. J. Stahl: None. P. Saalfeld: None. B. Behrendt: None. M. Thormann: None. A. Mpotsaris: None. B. Preim: None. P. Berg: None. S. Saalfeld: None.

\section{E-144 THE PRESENCE OF CEREBRAL EDEMA IN ADDITION TO RETROGRADE LEPTOMENINGEAL VENOUS DRAINAGE IN CRANIAL DURAL ARTERIOVENOUS FISTULAS IS AN INDICATOR OF CLINICAL SEVERITY}

I Nakagawa*, H Park, M Kotsugi, S Yokoyama, T Furuta, K Nakase, A Okamoto, S Yamada, H Nakase. Neurosurgery, Nara Medical University, Kashihara, Japan

\subsection{6/neurintsurg-2021-SNIS.239}

Purpose Retrograde leptomeningeal venous drainage (RLVD) in dural arteriovenous fistulas (DAVFs) is associated with intracerebral hemorrhage and nonhemorrhagic neurological deficits or death. Although angiographic evidence of RLVD is a definite indication for treatment, the addition of venous congestion to RLVD may cause severe clinical symptoms. In this study, we assessed parenchymal cerebral blood volume (PBV) to evaluate whether the presence of cerebral edema in addition to RLVD predicts the clinical severity in DAVFs.

Methods We retrospectively identified 53 patients who had angiographic evidence of RLVD and received treatment. The presence of cerebral edema was defined as cortical hyperintensity in FLAIR image. The PBV was obtained from rotational angiography and analyzed by workstation (syngo XWP vD $10 \mathrm{E})$.

Results In the cerebral edema group $(n=17)$, cerebral microbleeds, venous congestion ratio, PBV ratio, and shunt circulation time (SCT) were significantly increased $(p<0.001)$, and modified rankin scale $>2$ at discharge was significantly higher $(p=0.014)$. The preoperative PBV ratio was significantly correlated with the angiographic SCT and venous congestion ratios $(\mathrm{p}<0.001)$.

Conclusion Evaluation of PBV is useful for assessing focal venous congestion, and the presence of cerebral edema in addition to RLVD in DAVF can be an indicator of clinical severity.

Disclosures I. Nakagawa: None. H. Park: None. M. Kotsugi: None. S. Yokoyama: None. T. Furuta: None. K. Nakase: None. A. Okamoto: None. S. Yamada: None. H. Nakase: None.

\section{E-145 SAFETY OF PEDIATRIC CEREBRAL ANGIOGRAPHY}

${ }^{1} \mathrm{D}$ Lauzier*, ${ }^{2} \mathrm{~J}$ Osbun, ${ }^{2} \mathrm{~A}$ Chatterjee, ${ }^{3} \mathrm{C}$ Moran, ${ }^{2} \mathrm{~A}$ Kansagra. ${ }^{1}$ Mallinckrodt Institute of Radiology, Washington University School of Medicine, St. Louis, MO; ${ }^{2}$ Mallinckrodt Institute of Radiology, Department of Neurological Surgery, Department of Neurology, Washington University School of Medicine, St. Louis, MO; ${ }^{3}$ Mallinckrodt Institute of Radiology, Department of Neurological Surgery, Washington University School of Medicine, St. Louis, MO

10.1136/neurintsurg-2021-SNIS.240

Introduction/Purpose Catheter-based cerebral angiography is commonly used for neurovascular diagnosis in children. In this work, we aim to quantify the complication rate of cerebral angiography in children, characterize these complications, and identify risk factors for complications.

Materials and Methods Relevant clinical data were retrospectively obtained for 587 consecutive cerebral angiography procedures performed in 390 children from March 2002 to March 2020. Complications were categorized as neurologic or non-neurologic, and severity was graded using a standard schema. Incidences of complications are reported as point estimates. Associations between risk factors and complications were characterized in univariate analysis using the two-tailed 